Gut, 1987, 28, 613-615

Case report

\title{
Salicylate induced exacerbation of ulcerative colitis
}

\author{
T K CHAKRABORTY, D BHATIA, R C HEADING, AND M J FORD \\ From the Royal Infirmary, and Leith Hospital, Edinburgh
}

SUMmARY The oral administration of mesalazine (5-aminosalicylic acid) resulted in the exacerbation of ulcerative colitis in two patients intolerant to sulphasalazine whose colitis had previously been quiescent. Although sulphasalazine intolerance is usually attributable to the sulphapyridine moiety, the possibility of salicylate sensitivity should be considered in colitic patients who fail to respond appropriately to sulphasalazine or who experience abdominal pain or diarrhoea while taking the drug.

Mesalazine (Asacol, Tillotts Laboratories) is an oral 5 -aminosalicylic acid coated with an acrylic based resin (Eudragit $S$ ) which is released in the terminal ileum and colon. It has a similar clinical effect to sulphasalazine in maintaining remission in patients with ulcerative colitis and its use has been advocated in patients intolerant of sulphasalazine..$^{1-3}$ Exacerbation of diarrhoea and abdominal pain in patients receiving sulphasalazine for ulcerative colitis is unusual but well documented and has usually been attributed to the sulphapyridine moiety. ${ }^{+5}$ Ulcerative colitis, however, has been reported to be exacerbated by salicylate therapy alone. (.). $^{(-)}$We report two patients intolerant of sulphasalazine who developed a severe exacerbation of ulcerative colitis after the administration of 5-aminosalicylic acid.

\section{Case 1}

In June 1976, a 51 year old man (WM) was admitted to hospital with fever and bloody diarrhoea. The diagnosis of ulcerative panproctocolitis was established on barium enema, sigmoidoscopy and rectal biopsy and treatment with prednisolone $40 \mathrm{mg}$ /day and sulphasalazine $4 \mathrm{~g} /$ day introduced. Severe recurrent anaemia in the absence of bleeding or haemolysis and requiring blood transfusions, fever and the development of pleuritic chest pain with

Address for correspondence: Dr M J Ford. Leith Hospital Mill Lane. Edinburgh.

Received for publication 16 September 1986. an effusion necessitated the withdrawal of sulphasalazine. Anaemia and colitic symptoms resolved after six weeks hospitalisation and he was discharged home. Follow up over the ensuing eight years was uneventful.

In June 1984, further hospitalisation and prednisolone therapy was necessitated by a relapse and on review in February 1985 he was asymptomatic. There was no antecedent history of atopy, asthma, eczema, or rhinitis. Mesalazine, 5-aminosalicylic acid, (Asacol) $400 \mathrm{mg}$ tid was then introduced. Five days later, he developed a fever with severe bloody diarrhoea, nausea, and vomiting. Sigmoidoscopy releaved the macroscopic changes of an active colitis and an anal fissure. The withdrawal of mesalazine together with iv fluids resulted in a prompt clinical improvement and a normal temperature chart. Four days later mesalazine $400 \mathrm{mg}$ tid was reintroduced and within 24 hours he had developed rigors, temperature $39.6^{\circ} \mathrm{C}$, bloody diarrhoea, nausea, vomiting and an erythematous macular rash associated with mouth ulcers and synovitis of a wrist joint. Antibiotic and prednisolone therapy was introduced although he failed to improve until mesalazine was subsequently withdrawn.

Initial laboratory investigations revealed normal full blood count, liver function values and serum proteins. Eight days after the reintroduction of 5 -aminosalicylic acid, however, the haemoglobin had fallen from $11.9 \mathrm{~g} / \mathrm{dl}$ to $8.4 \mathrm{~g} / \mathrm{dl}$ with a normal differential count and reticulocyte count of $2 \%$, the serum albumin had fallen from $39 \mathrm{~g} / 1$ to $25 \mathrm{~g} / 1$ and the 
serum alkaline phosphatase and gamma glutamyl transferase had risen from $60 \mathrm{IU} / 1$ and $19 \mathrm{IU} / 1$ respectively to $144 \mathrm{IU} / 1$ and $104 \mathrm{IU} / 1$. Viral and bacteriological screening tests were unremarkable and antinuclear antibodies were not detectable.

Two weeks after the introduction of prednisolone $40 \mathrm{mg} /$ day and the withdrawal of mesalazine he was asymptomatic: prednisolone therapy was gradually withdrawn. Six months later, he remains asymptomatic.

\section{Case 2}

In April 1980, a 21 year old woman (EJ) was admitted to hospital with a four month history of lower abdominal pain, diarrhoea, anorexia, and weight loss. There was no antecedent history of atopy, asthma, eczema or rhinitis. The diagnosis of distal ulcerative proctocolitis was established on barium enema, sigmoidoscopy and rectal biopsy. Sulphasalazine therapy, $3 \mathrm{~g} /$ day, was withdrawn because of nausea, vomiting, and abdominal pain. After an uneventful recovery after prednisolone therapy $30 \mathrm{mg} / \mathrm{day}$ her symptoms remained well controlled over the ensuing three years on prednisolone therapy $5 \mathrm{mg} /$ day.

In May 1983, she was readmitted with a severe exacerbation of colitis which responded well to oral and rectal prednisolone therapy. Sulphasalazine was gradually reintroduced and for four months, symptoms were well controlled without prednisolone therapy. Nausea, vomiting, abdominal pain and diarrhoea recurred, however, with sigmoidoscopic evidence of active colitis. Prednisolone therapy and the withdrawal of sulphasalazine resulted in good symptomatic control. In January 1984 while on prednisolone $10 \mathrm{mg}$ daily, sulphasalazine desensitisation was attempted but nausea and diarrhoea recurred at a dosage of $500 \mathrm{mg}$ daily. Because of a continuing mild distal proctocolitis and steroid dependency, mesalazine $800 \mathrm{mg}$ tid was introduced in August 1984. Within 24 hours, she developed explosive watery diarrhoea, abdominal pain, gaseous colonic distension and pruritus. Sigmoidoscopy showed minimal reactive changes only; the mesalazine was withdrawn and all symptoms resolved. One week later, mesalazine $400 \mathrm{mg}$ tid was reintroduced resulting in further abdominal pain, distension and watery diarrhoea necessitating its withdrawal. The full blood count, differential WBC count, serum albumin and liver function values remained normal throughout.

Over the ensuing three months, oral prednisolone was withdrawn uneventfully. By August 1985 she was asymptomatic and the sigmoidoscopic appearances were normal.

\section{Discussion}

Sulphasalazine consists of sulphapyridine and 5-aminosalicylic acid linked by a diazo bond. Adverse reactions to sulphasalazine are common and may be dose related or idiosyncratic in origin. Most hypersensitivity reactions, however, have been attributed to the sulphapyridine moiety and include the gastrointestinal side effects of nausea, vomiting, abdominal pain, and diarrhoea. ${ }^{10-11}$ The predominantly satisfactory response of sulphasalazine intolerant patients to 5-aminosalicylic acid supports this view. ${ }^{3}$

The exacerbation of colitic symptoms in response to oral or rectal sulphasalazine is unusual but well recognised. ${ }^{+5}$ The similar occurrence of abdominal pain and bloody diarrhoea after 5-aminosalicylic acid therapy in our patients and in two patients previously reported suggests that this pattern of sulphasalazine intolerance may in fact be caused by the 5-aminosalicylic acid moiety of the molecule.' A total of 29 patients developing diarrhoea in response to 5-aminosalicylic acid have been reported to date. (Tillots Laboratories-personal communication).

The patients we describe may illustrate different phenomena. The first case developed an exacerbation of colitis in association with a generalised hypersensitivity reaction to 5-aminosalicylic acid whereas in the second case, diarrhoea and abdominal pain followed exposure to the drug without other evidence of hypersensitivity. Approximately one in five of patients reported to Tillotts Laboratories with diarrhoea in response to mesalazine had evidence of a generalised hypersensitivity reaction usually a fever and/or a skin rash. A similar experience has been well recorded in patients given para-aminosalicylic acid in the treatment of tuberculosis. Nausea, vomiting, and diarrhoea occur in $8 \%$ of such patients of whom less than one third experience allergic manifestations such as fever or skin rash. ${ }^{2}$ Fever, skin rash and bloody diarrhoea have been reported in a patient given para-aminosalicylic acid. ${ }^{13}$

Thus, although salicylate induced diarrhoea occurs with a spectrum of severity ranging from the nonspecific to florid hypersensitivity disorders, it is possible that there are overlapping subpopulations in whom allergic and idiosyncratic, dose related phenomena are involved. Proctocolitis has been shown to be exacerbated by acetylsalicylic acid in one atopic individual whose bowel symptoms could not subsequently be induced by sulphapyridine." Nonsteroidal anti-inflammatory drugs have been shown to precipitate relapse in four patients with inactive ulcerative proctocolitis. ${ }^{x}$ Studies examining analgesic ingestion in colitic patients before the onset of relapse compared with that of colitics in remission indicate a significantly higher prevalence of para- 
cetamol and salicylate ingestion before relapse. Such an association could be explained by the selective and idiosyncratic inhibitory effects of non-steroidal antiinflammatory drugs on mucosal prostaglandin synthesis and degradation."

Although 5-aminosalicylic acid is a useful alternative therapy in most sulphasalazine intolerant patients, the possibility of salicylate sensitivity should be remembered in atopic individuals, patients who fail to respond appropriately to sulphasalazine and especially in patients who have previously experienced abdominal pain or diarrhoea while taking the drug.

We are grateful to Dr R A Oakes, Tillotts Laboratories, for his information and assistance in the preparation of the manuscript.

\section{References}

1 Dew MJ, Hughes P, Harries AD, Williams G, Evans BK, Rhodes J. Maintenance of remission in ulcerative colitis with oral preparation of 5-amino salicylic acid. Br Med J 1982; 285: 1012-4.

2 Dew MJ, Harries AD, Evans N, Evans BK, Rhodes J. Maintenance of remission in ulcerative colitis with 5 -amino salicylic acid in high doses by mouth. Br Med J 1983; 287: 23-4.

3 Dew MJ, Harries AD, Evans BK, Rhodes J. Treatment of ulcerative colitis with oral 5-amino salicylic acid in patients unable to take sulphasalazine. Lancet 1983; ii: 801 .

4 Werlin SL, Grand RJ. Bloody diarrhoea-a new complication of sulphasalazine. J Paediatr 1978; 92: 450-1.

5 Schwartz AG, Targan SR, Saxon A, Weinstein WM. Sulphasalazine-induced exacerbation of ulcerative colitis. N Engl J Med 1982; 306: 409-12.

6 Pearson DJ, Stones NA, Bentley SJ, Reid H. Proctocolitis induced by salicylate and associated with asthma and recurrent nasal polyps. Br Med J 1983; 287: 1675.

7 Austin CA, Cann PA, Jones TH, Holdsworth CD. Exacerbation of diarrhoea and pain in patients treated with 5-amino salicylic acid for ulcerative colitis. Lancet 1984; i: 917.

8 Rampton DS, Sladen GE. Relapse of ulcerative proctocolitis during treatment with non-steroidal antiinflammatory drugs. Postgrad Med J 1981; 57: 297-9.

9 Rampton DS, McNeil NI, Sarner M. Analgesic ingestion and other factors preceding relapse in ulcerative colitis. Gut 1983; 24: 187-9.

10 Das KM, Eastwood MA, McManus JPA, Sircus W. Adverse reactions during salicylazosulphapyridine therapy and the relation with drug metabolism and acetylator phenotype. N Engl J Med 1973; 289: 491-5.

11 Taffet SL, Das KM. Sulphasalazine-adverse effects and desensitisation. Dig Dis Sci 1983; 28: 833-42.

12 Berte SJ, DiMase JD, Christianson CS. Isoniazid, paraaminosalicylic acid and streptomycin intolerance in 1744 patients. Am Rev Resp 1964; 90: 598-606.

13 Warring FC, Howlett JR. Allergic reactions to paraaminosalicylic acid. Report of seven cases including one case of Loeffler's syndrome. Am Rev Tuberc 1952; 65: 235-49. 